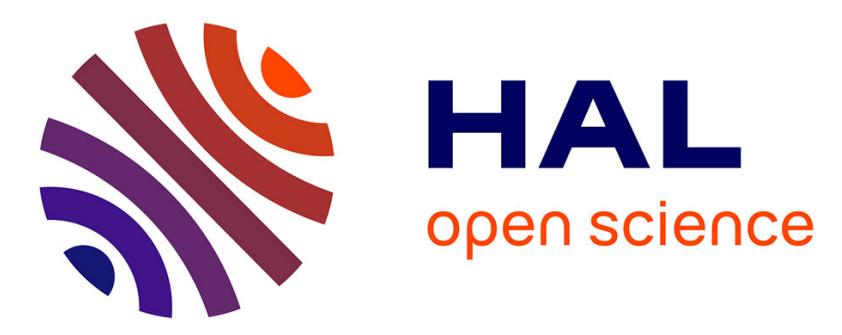

\title{
On the second language acquisition of Spanish reflexive passives and reflexive impersonals by French- and English-speaking adults
}

Annie Tremblay

\section{- To cite this version:}

Annie Tremblay. On the second language acquisition of Spanish reflexive passives and reflexive impersonals by French- and English-speaking adults. Second Language Research, 2006, 22 (1), pp.30-63. 10.1191/0267658306sr260oa . hal-00572093

\section{HAL Id: hal-00572093 \\ https://hal.science/hal-00572093}

Submitted on 1 Mar 2011

HAL is a multi-disciplinary open access archive for the deposit and dissemination of scientific research documents, whether they are published or not. The documents may come from teaching and research institutions in France or abroad, or from public or private research centers.
L'archive ouverte pluridisciplinaire HAL, est destinée au dépôt et à la diffusion de documents scientifiques de niveau recherche, publiés ou non, émanant des établissements d'enseignement et de recherche français ou étrangers, des laboratoires publics ou privés. 


\section{On the second language acquisition of Spanish reflexive passives and reflexive impersonals by French- and English-speaking adults}

\section{Annie Tremblay University of Hawai'i at Manoa}

Received May 2003; revised October 2004; accepted November 2004

This study, a partial replication of Bruhn de Garavito (1999a; 1999b), investigates the second language (L2) acquisition of Spanish reflexive passives and reflexive impersonals by French- and English-speaking adults at an advanced level of proficiency. The L2 acquisition of Spanish reflexive passives and reflexive impersonals by native French and English speakers instantiates a potential learnability problem, because (1) the constructions are superficially very similar (se V DP) but display distinct idiosyncratic morphological and syntactic behaviour; (2) neither exists in English, and the reflexive impersonal does not exist in French; and (3) differences between the two are typically not subject to explicit instruction. Participants - 13 English, 16 French and 27 Spanish speakers (controls) - completed a 64-item grammaticality-judgement task. Results show that L2 learners could in general differentiate grammatical from ungrammatical items, but they performed significantly differently from the control group on most sentence types. A look at the participants' accuracy rates indicates that few L2 learners performed accurately on most sentence types. Grammatical and ungrammatical test items involving [+ animate] DPs preceded or not by the object-marking preposition $a$ were particularly problematic, as L2 learners judged them both as grammatical. These results confirm that the L2 acquisition of Spanish reflexive passives and reflexive impersonals by French- and English-speaking adults instantiates a learnability problem, not yet overcome at an advanced level of proficiency. 


\section{Introduction}

A substantial number of studies in second language (L2) acquisition have shown that L2 learners come to acquire the grammatical constraints of structures that are neither present in their first language (L1) nor salient in the input (e.g. Schreiber and Sprouse, 1998; Kanno, 1999; Dekydtspotter and Sprouse, 2001). Spanish reflexive passives and reflexive impersonals are a good example of two different constructions that instantiate a potential learnability problem, because they are superficially very similar - i.e. they both display the sequence se V DP - but they each have idiosyncratic morphological and syntactic behaviour:

1) a. Se contrataron los mejores profesores del país. (reflexive passive) SE.ACC hired-PL the the best teachers.NOM of the country

'The best teachers in the country were hired.'

b. Se contrató a los mejores profesores del país. (reflexive impersonal)

SE.NOM hired-SG A the best teachers.ACC of the country

'The best teachers in the country were hired.'

In the analysis adopted herein, se in reflexive passives checks accusative case, and the internal argument (DP) bears nominative case and triggers agreement on the verb. This is shown in (1a), where the plural subject los mejores profesores del país 'the best teachers in the country' triggers plural agreement on the verb contrataron 'hired-PL'. In contrast, se in reflexive impersonals checks nominative case and the internal argument (DP) bears accusative case (e.g. Belletti, 1982; Tremblay, 2002). This is illustrated in (1b), where $s e$ is the subject and triggers default (third-person) singular agreement on the verb contrató 'hired-SG'. Furthermore, in Spanish [+animate] direct objects are preceded by the object-marking preposition $a$. This explains why the internal argument los mejores profesores del país 'the best teachers in the country' in (1b), which checks accusative case, must be preceded by $a$.

Very few studies have been conducted on the L2 acquisition of Spanish reflexive passives and reflexive impersonals. Bruhn de Garavito (1999a; 1999b) carried out an experiment on the L2 acquisition of reflexive passive, reflexive impersonal and alternating causative/inchoative constructions by advanced English and near-native French and English speakers of Spanish. She found that L2 learners' 
grammaticality judgements were indistinguishable from those of the control group. On this basis, she argues that L2 learners must have acquired the properties of reflexive passives and reflexive impersonals. The problem with this conclusion is that the participants in her Control group were from a variety of Spanish-speaking countries, and her grammaticality judgement task included items that are subject to dialectal variation. On those items, neither the Control group nor the L2 learners were uniform in their responses, with half of them accepting and half of them rejecting the constructions subject to dialectal variation. In this case, because Bruhn de Garavito does not specify to which variety of Spanish the L2 learners were exposed, it is not clear whether they accepted certain constructions as a result of dialectal variation or because they had not acquired the structural and thematic properties of reflexive passives and reflexive impersonals.

This study, a partial replication of Bruhn de Garavito's (1999a; 1999b) study, investigates the L2 acquisition of Spanish reflexive passives and reflexive impersonals by advanced French- and Englishspeaking adults. ${ }^{1}$ Its primary objective is to determine whether L2 learners can acquire the structural and thematic properties underlying se and the internal argument (DP) in reflexive passives and reflexive impersonals. Importantly, this study differs from Bruhn de Garavito's study in three respects. First, our participants have been assessed to be at an advanced level of proficiency, in contrast to Bruhn de Garavito's (1999a; 1999b) participants, who included one advanced and two nearnative experimental groups. This means that the interlanguage grammar of our L2 learners is unlikely to be at its end state yet. Second, some of the test items on which our participants were tested differ from those used in Bruhn de Garavito's grammaticality judgement task. Details on these differences are provided in Section V. Last but not least, our participants have learned Spanish as a foreign language in an instructional setting in Canada. Although one may not completely exclude the possibility that the L2 learners in this study have been exposed to different dialectal variations of Spanish, the experimental groups have received instruction on standard Spanish only. Since our participants

\footnotetext{
${ }^{1}$ Note that Spanish is actually the third language of most of the participants. However, for reasons of convenience, the term 'second language' (or L2) is used throughout this article.
} 
did not have extensive exposure to Spanish outside Canada, it seems reasonable to assume that dialectal variation should not be part of their grammar.

The article is organized as follows: Section II provides an account of reflexive passives and reflexive impersonals in terms of the structural and thematic properties of se and the internal argument; Section III analyses both constructions within a minimalist framework; Section IV reviews Bruhn de Garavito's (1999a; 1999b) study on the L2 acquisition of reflexive passives and reflexive impersonals; Section V covers the details of the present experiment and presents its results; and Section VI discusses the significance of these results.

\section{Properties of Spanish reflexive passives and reflexive impersonals}

\section{Reflexive passives}

One way of expressing the passive in Spanish, common to all Romance languages and preferred over the 'full passive constructions ${ }^{2}$ is the reflexive passive exemplified in (2a) and (2b), which is formed with the internal argument ${ }^{3}$ of the verb (los libros 'the books') appearing in a pre- or post-verbal position, the reflexive marker se and the verb in its active form (vendieron 'sold'):

2) a. Los libros se vendieron rápidamente.

the books.NOM SE sold-PL quickly

'The books were sold quickly.'

b. Se vendieron rápidamente los libros.

SE sold-PL quickly the books.NOM

'The books were sold quickly.'

2I use the term 'full passive constructions' (Perlmutter and Postal, 1984) to refer to structures which combine the copula ser in Spanish and the past participle of the verb, where the internal argument occupies the subject position and where the Agent (if expressed) is embedded in a Prepositional Phrase introduced by por:
i) El pastel fue comido
por los niños.
the cake.NOM was eaten-MASC.SG by the children
'The cake was eaten by the children.'

${ }^{3}$ The term 'internal argument' is used to refer to any DP that is marked with accusative case in a regular active sentence, but that does not check such case in the reflexive passive. Such a distinction is necessary, for the DP in reflexive passives is not marked with accusative case, as is demonstrated later in this section. 
In (2a)-(2b), the internal argument los libros 'the books' is the subject and triggers plural agreement on the verb vendieron 'sold-PL'. In Spanish, subjects are licensed in a pre- or post-verbal position. Reflexive passives do not have an external argument in subject position; instead, the subject (here los libros 'the books') undergoes the action(s) manifested by some implied Agent (the external argument, unexpressed).

Among various analyses proposed to account for reflexive passives (e.g. Belletti, 1982; Burzio, 1986; Raposo and Uriagereka, 1996; Dobrovie-Sorin, 1998), Belletti (1982) attributes two crucial properties to reflexive passive $s e$. First, $s e$ is associated with the external thetarole ( $\theta$-role) of the verb otherwise assigned to the subject of a regular active sentence. This association is supported by the fact that the external argument cannot be expressed in an agentive PP introduced by por 'by':

3) * Los libros de la conferencia se vendieron por algunos estudiantes. the conference books.NOM SE sold-PL by some students

As shown in (3), reflexive passives cannot co-occur with an agentive PP, because $s e$ is already assigned the external $\theta$-role of the verb, which leaves algunos estudiantes 'some students' without a $\theta$-role. Yet, the presence of a covert Agent is apparent, as it controls PRO in reflexive passives followed by an infinitival purpose clause:

4) Los libros de la conferencia se vendieron PRO para promover la investigación en el medio académico.

the conference books.NOM SE sold-PL PRO to promote research in academic environments

'The conference books were sold to promote research in academic environments.'

In (4), it is understood that PRO is not an arbitrary one; it is controlled by an implied Agent, whoever sold the books. Thus, the only element that may receive the external $\theta$-role in the sentence is $s e$, since the subject DP (or internal argument) is already assigned the internal $\theta$-role, that of Theme.

Another property of reflexive passive se observed by Belletti (1982) is that it checks the accusative case otherwise checked by the direct object. As a result, the internal argument, which may no longer check accusative case, must check nominative case. This is supported by the fact that the DP in reflexive passives triggers agreement on the verb (2a), it can be dropped (5a), but it cannot be 
replaced by a direct object clitic pronoun (5b) (Bruhn de Garavito, 1999a; 1999b):

\begin{tabular}{|c|c|c|c|}
\hline $\begin{array}{l}\text { a. ¿Los } \operatorname{libros}_{\mathrm{i}} ? \\
\text { the books? }\end{array}$ & $\begin{array}{l}\text { pro }_{\mathrm{i}} \\
\text { pro.NOM }\end{array}$ & $\begin{array}{l}\mathrm{Se} \\
\text { SE.ACC }\end{array}$ & $\begin{array}{l}\text { vendieron. } \\
\text { sold-PL }\end{array}$ \\
\hline The books? & hey were & sold.' & \\
\hline $\begin{array}{l}\text { b. ¿Los } \operatorname{libros}_{\mathrm{i}} \text { ? } \\
\text { the books? }\end{array}$ & $\begin{array}{l}* \mathrm{Se} \\
\text { SE.ACC }\end{array}$ & $\begin{array}{l}\operatorname{los}_{\mathrm{i}} \\
\text { them.ACC }\end{array}$ & old-PL \\
\hline
\end{tabular}

The idea that $s e$ checks accusative case is also supported by the fact that unergative, unaccusative and copulative verbs cannot co-occur with reflexive passive se since they cannot have a direct object, as illustrated in (6):

$\begin{array}{cll}\text { 6) a. * Ayer, } & \text { Juan } & \text { se lloró. } \\ \text { yesterday } & \text { Juan.NOM } & \text { SE.ACC cried-SG } \\ \text { b. * Ayer, } & \text { los libros } & \text { se llegaron. } \\ \begin{array}{c}\text { yesterday } \\ \text { the books.NOM }\end{array} & \text { SE.ACC arrived- PL } \\ \text { c. * Ayer, } & \text { Juan } & \text { se estaba furioso. } \\ \text { yesterday } & \text { Juan.NOM } & \text { SE.ACC was furious }\end{array}$

These examples show that reflexive passives may be formed only with verbs that can assign accusative case.

Whether it is difficult for native speakers of French and English to learn Spanish reflexive passives may depend on the typological proximity of L1 and L2, assuming that L1 transfer may facilitate or inhibit L2 acquisition (e.g. Schwartz and Sprouse, 1994; 1996). On the one hand, Spanish reflexive passives obey the same constraints as their French counterparts, except that the subject DP in French reflexive passives may only appear in pre-verbal position, as shown in (7):

7) a. * Les livres se sont vendus rapidement.
the books.NOM SE.ACC are sold-PL quickly
'The books were sold quickly.'
$\begin{array}{rlll}\text { b. * } & \text { Se sont vendus rapidement les livres. } \\ & \text { SE.ACC are sold-PL quickly } & \text { the books.NOM }\end{array}$

On the other hand, Spanish differs from English, in that English does not have a reflexive marker such as se to express the passive. Instead, English combines the copula be and the past participle - en to form the 'full' passive morphology. Full passive constructions differ from reflexive passives not only in terms of morphology (the latter using an 'active' verb form), but also because the former can appear with an agentive PP in (8), since the external $\theta$-role is not assigned to any argument in the sentence:

8) The conference books were sold by a few students. 
Hence, the typological proximity of Spanish and French (as opposed to English) may increase the ease with which French-speaking L2 learners will acquire Spanish reflexive passives.

\section{Reflexive impersonals}

Despite their similar superficial realizations, reflexive impersonals exhibit different properties from reflexive passives. First, only reflexive impersonals may be formed with unergative, unaccusative and copulative verbs, as illustrated in $(9 \mathrm{a}-\mathrm{c})$, respectively:

9) a. Siempre se llora en esta película. always SE.NOM cries during this movie 'One always cries // We always cry during this movie.'

b. Aquí nunca se llega con retraso. here, never SE.NOM arrives late

'Here, one never arrives // we never arrive late.'

c. En esta oficina, siempre se está furioso. in this office always SE.NOM is furious 'In this office, one is // we are always furious.'

In $(9 \mathrm{a}-\mathrm{c})$, it is se that checks nominative case and triggers default (third person singular) agreement on the verb. Some varieties of Spanish also allow reflexive impersonals to be formed with transitive verbs whose internal argument is [-animate], as shown in (10): ${ }^{4}$

10) Aquí se vende libros de lingüística.

here SE sells books of linguistics.ACC

'Here one sells // we sell linguistics books. // Here linguistics books are sold.'

In contrast to reflexive passives, the internal argument in reflexive impersonals checks accusative case. As a result, it must be preceded by the object-marking preposition $a$ when [+animate], and it can be replaced by a direct object complement (Hernanz and Brucart, 1987; Bruhn de Garavito, 1999a; 1999b). These two supporting facts are exemplified in $(11 \mathrm{a}-\mathrm{b})$ :

11) a. Aquí se encuentra a muchos autores.

here SE.NOM meets A many authors.acc

'Here one meets // we meet many authors.'

${ }^{4}$ For example, speakers from certain areas of Argentina accept and produce reflexive impersonals with a post-verbal [ - animate] DP. Traditionally, speakers from Spain would, for the most part, reject sentences where agreement between the verb and the post-verbal DP is not present (Bosque and Demonte, 1999: 1676). However, this tendency has been changing over the last few decades, and reflexive impersonals followed by a post-verbal [-animate] DP are becoming more and more common (Christian Abello-Contesse and Mercedes Torres Cansino, personal communication, November 2003). 

b. Aquí se los encuentra.
here SE.NOM them.ACC meet-SG
'Here one meets // we meet them.'

Because the internal argument is marked with accusative case, it cannot be dropped in (12), since object drop is not permitted in Spanish:

12) Aquí se encuentra.

here SE.NOM meets

The substitution of the internal argument for a direct object clitic pronoun, the insertion of the object-marking preposition $a$, and the impossibility for the internal argument to be dropped are direct consequences of the fact that the internal argument (thus not se) bears accusative case.

Spanish reflexive impersonals possess a syntactic structure very similar to their French and English counterparts. Nevertheless, French requires the use of the pronoun nous 'we' or on 'one' (or sometimes tu 'you')as the subject of the sentence, depending on whether the speaker is included or not. Likewise, English uses the pronoun we or one (or sometimes you). Examples of impersonals in French and English are provided in $(13 \mathrm{a}-\mathrm{b})$, respectively:

13) a. Ici, on vend // nous vendons des livres de linguistique. here one sells // we sell some books of linguistics 'Here one sells // we sell linguistic books // Linguistic books are sold.'

b. Here one sells // we sell linguistic books.

Importantly, neither French nor English has a reflexive marker that allows either language to form reflexive impersonals.

The properties of se and the internal argument in reflexive passives and reflexive impersonals, as discussed in this section, are summarized in Table 1. The L2 acquisition of the properties outlined in Table 1 may give rise to a learnability problem for French and English L2 learners of Spanish, not only because reflexive passives and reflexive

Table 1 Properties of reflexive passives and reflexive impersonals (summary)

\begin{tabular}{|c|c|c|c|c|}
\hline & \multicolumn{2}{|c|}{ Reflexive passive } & \multicolumn{2}{|c|}{ Reflexive impersonal } \\
\hline & se & $\mathrm{DP}$ & se & DP (when present) \\
\hline $\begin{array}{l}\text { Thematic } \\
\text { properties }\end{array}$ & $\begin{array}{l}\text { External } \theta \text {-role } \\
\quad \text { (Agent) }\end{array}$ & $\begin{array}{l}\text { Internal } \theta \text {-role } \\
\quad \text { (Theme/Patient) }\end{array}$ & $\begin{array}{l}\text { External } \theta \text {-role } \\
\text { (Agent) }\end{array}$ & $\begin{array}{l}\text { Internal } \theta \text {-role } \\
\quad \text { (Theme/Patient) }\end{array}$ \\
\hline $\begin{array}{l}\text { Structural } \\
\text { properties }\end{array}$ & Accusative case & Nominative case & Nominative case & Accusative case \\
\hline
\end{tabular}


impersonals are very similar, but also because neither French nor English has constructions that are the exact grammatical counterparts. It is precisely this learnability problem that L2 learners must overcome.

\section{A minimalist account of native speakers' competence}

According to the Minimalist Program (Chomsky, 1995), the argument structure of verbs in languages allowing object agreement is formed with a light $\nu \mathrm{P}$ and $\mathrm{VP}$, with the former projecting two specifier positions: the inner specifier where the external argument is merged and the outer specifier where the internal argument will later move to trigger object agreement, as shown in (14):

14) Argument structure of Spanish verbs:

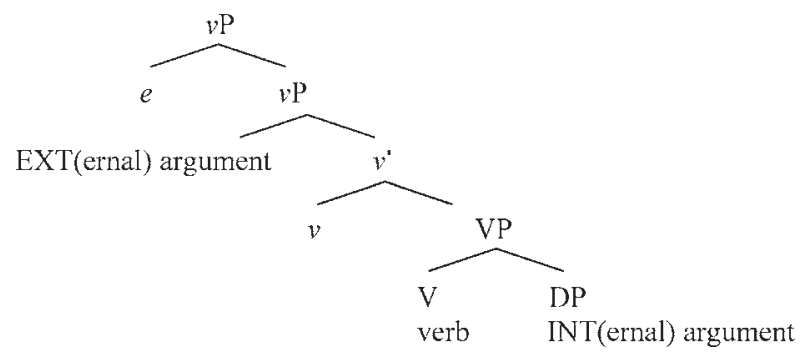

I assume (14) to be the basic structure of Spanish, with an inner specifier position where the external argument is merged and an outer specifier position $(e)$ where the internal argument will later move to check its nominative case feature and trigger agreement on the verb. In Spanish, only the outer specifier position of $v \mathrm{P}$ is specified for [assign nominative case]. ${ }^{5}$ Departing from the original Minimalist Program and following Raposo and Uriagereka (1996), case features, phi-features, categorical features and strength of features are specified within the light $v \mathrm{P}$ instead of a regular VP.

The analysis I propose to account for reflexive passives and reflexive impersonals is inspired from Rivero (2001). In reflexive passives, se is

\footnotetext{
${ }^{5} \mathrm{An}$ increasing number of researchers argue that $\mathrm{T}$ in Spanish and some other null subject languages does not project a specifier position (e.g. Olarrea, 1996; Ordóñez, 1997). Instead, the subject checks nominative case in situ under [Spec, $v \mathrm{P}]$ and moves to a Topic Phrase or Clitic Left Dislocation phrase when it appears in a pre-verbal position. I assume this analysis to be an adequate account of the syntactic representation of subject DPs in Spanish.
} 
merged under a Clitic Phrase (CIP) in $v \mathrm{P}$ as a defective element and needs to combine with a null NP (henceforth $\mathrm{nP}$, here, projected in the inner specifier position of $v \mathrm{P})$ to repair its 'referential imperfection' (Rivero, 2001: 172), ${ }^{6}$ as illustrated in (15):

15) A representation for se:

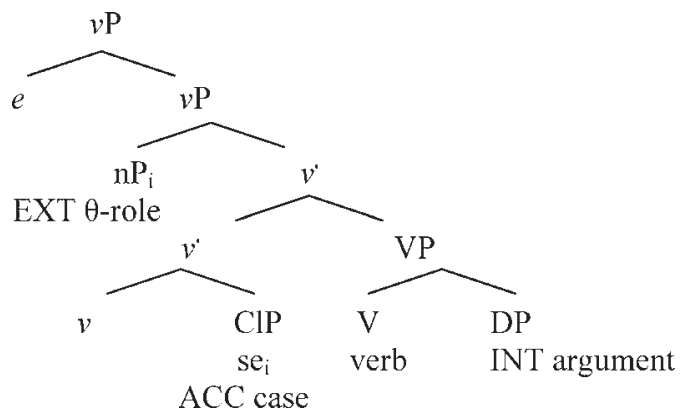

In this case, $\mathrm{nP}$ has a [+human] feature specification, no case specification, and it is associated with the external $\theta$-role of the verb. $S e$, on the other hand, has a case specification but no $\theta$-role, as it is referentially defective. CIP is specified for [assign accusative case]. By moving $\mathrm{nP}$ to se at Logical Form (LF), nP repairs the referentiality of se and allows it to be an argument in the syntactic structure and check its accusative case. Another property of $v \mathrm{P}$ is that it is [+Strong] and attracts the verb to its head before the verb moves to Tense, as shown in (16):

16) Se vendieron los libros.

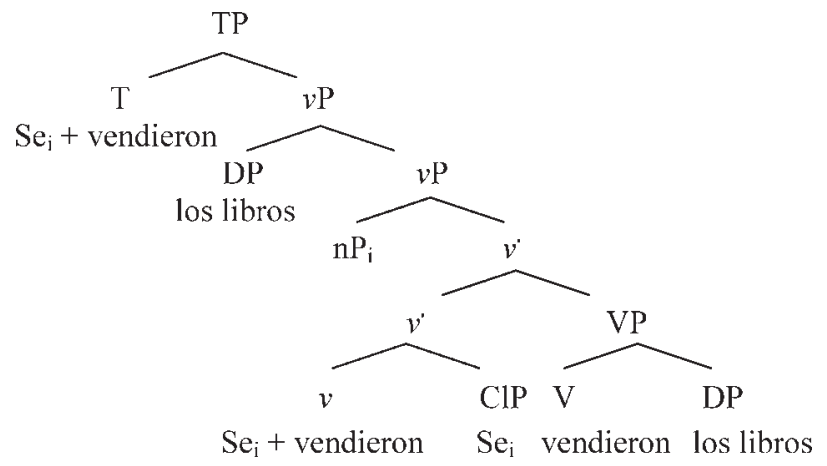

${ }^{6}$ Rivero's (2001) analysis was put forward to account for reflexive impersonals (rather than reflexive passives) as is shown later in this section. 
It is during this movement that se cliticizes to the verb. The outer specifier position of $v \mathrm{P}$, which is specified for [D] and [assign nominative case], then triggers the overt movement of the internal argument and verb agreement. When the internal argument appears in a pre-verbal position, it moves from the outer specifier of $v \mathrm{P}$ to a Topic Phrase, since it has already checked its nominative case feature (Raposo and Uriagereka, 1996; Bruhn de Garavito, 1999a; 1999b).

As for reflexive impersonals, se is again a defective element that cooccurs with an $\mathrm{nP}$ in the inner specifier position of $\nu \mathrm{P}$ (Reinhart and Reuland, 1993; Rivero, 2001). This time, se is merged outside $v \mathrm{P}$ in a ClP dominating TP, as illustrated in (17): ${ }^{7}$

17) $\mathrm{ClP}$

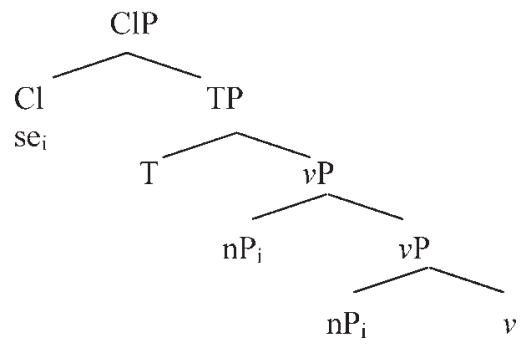

Again, $\mathrm{nP}$ is merged in the inner specifier position of $v \mathrm{P}$; it has a [+human] feature, no case specification, and it is associated with the external $\theta$-role of the verb. $S e$, on the other hand, has a case specification and it is referentially defective. Note that this differs from Rivero (2001), in that it is the reflexive marker (and not nP) that has a case specification. To repair the referentiality of the se, $\mathrm{nP}$ adjoins to se at LF. After this covert movement, se becomes an argument in the syntactic structure and needs to check a case. Since the outer specifier position of $v \mathrm{P}$ is specified for [assign nominative case], it attracts the closest argument available in the computation, i.e. nP. It is through the chain it forms at LF with $\mathrm{nP}$ that se can check its nominative case feature. Agreement remains third person singular because se has no phifeatures. Let us take for example sentence (9a) repeated in (18):

18) Siempre se llora en esta película. always SE.NOM cries during this movie 'One always cries // we always cry during this movie.' 
In a reflexive impersonal such as (18), se is merged in a clitic position dominating $\mathrm{T}$ and co-indexed with $\mathrm{nP}$ in the inner specifier position of $\nu \mathrm{P}$, where it is associated with the external $\theta$-role of the verb. $\mathrm{nP}$ moves covertly to se to repair the 'referential imperfection' of $s e$ (to borrow Rivero's terminology) and allow it to check nominative case, as illustrated in (19):

19)

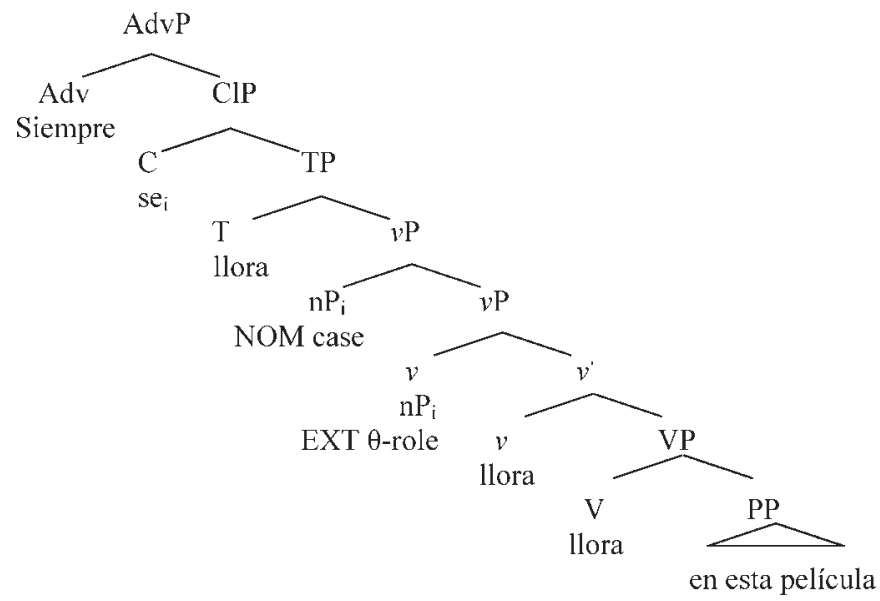

As for verbs that do not project an external $\theta$-role (such as unaccusative, passive and copulative verbs), se should be co-indexed with an $\mathrm{nP}$ complement of $\mathrm{V}^{\prime}$, where it receives the internal $\theta$-role and stands for the internal rather than the external argument. In terms of movement, the principles are the same as in (18): $\mathrm{nP}$ adjoins to se covertly so that the case features of ClP may be checked and deleted.

The common property of the two analyses developed here is that se in both reflexive passives and reflexive impersonals isassociated at LF with the external $\theta$-role of the verb. What differentiates the two constructions is the position in which se is merged and the case it checks. In reflexive passives, se is merged in a ClP projected within $v \mathrm{P}$ and checks accusative case; in reflexive impersonals, se is merged in a $\mathrm{ClP}$ dominating $\mathrm{T}$ and checks nominative case.

\section{Previous research on the L2 acquisition of Spanish se}

It is only recently that the L2 acquisition of Romance reflexive constructions within a generative framework has received the attention 
of L2 researchers (e.g. Montrul, 1997; 1999; Toth, 1998; 1999; Bruhn de Garavito, 1999a; 1999b). Bruhn de Garavito (1999a, 1999b) investigated the acquisition of reflexive impersonal, reflexive passive and alternating causative/inchoative constructions by French- and Englishspeaking L2 learners of Spanish. Her participants included 10 English advanced speakers of Spanish, 10 English near-native speakers of Spanish, 10 French near-native speakers of Spanish and a Control group made up of 11 native speakers of Spanish from Columbia (4), Mexico (3), Spain (1), Peru (1), El Salvador (1) and Guatemala (1). They completed a grammaticality judgement task of 90 items (50 grammatical and 40 ungrammatical), based on a five-point scale (-2 'sounds bad'; -1 'sounds bad, but not so much'; 0 'you cannot decide: try to avoid this answer'; 1 'sounds relatively good'; and 2 'sounds good').

The test items assessing the participants' knowledge of reflexive passives and reflexive impersonals are presented in Table 2. They include grammatical and ungrammatical reflexive passives with a preverbal [-animate] subject DP, grammatical reflexive impersonals with a post-verbal [+animate] object DP and ungrammatical reflexive passives with a post-verbal [+animate] subject DP. ${ }^{8}$ The reflexive passive in (b) in Table 2 is ungrammatical, because the verb is third person singular and should be third person plural, given the plural subject unas casas 'some houses'; and the reflexive passive in (d) is ungrammatical, because the object marking preposition $a$ should not precede [+ animate] subjects, but [ + animate] objects. Bruhn de Garavito (1999a; 1999b) did not categorize (d) asungrammatical, as it is produced and accepted in (a few) Spanish dialects. ${ }^{9}$

Table 3 indicates the number of Bruhn de Garavito's (1999a; 1999b) participants who gave a judgement ranging from -0.5 to +2 on the four sentence types. The results show that the participants in the

${ }^{8}$ Note that only the test items from Bruhn de Garavito (1999a; 1999b) that are pertinent to this study are presented, and they are labelled differently here, for consistency with the previous analyses. Bruhn de Garavito's (1999a; 1999b) study included many more sentence types, which is not discussed due to space limitations.

${ }^{9}$ Nevertheless, it is not clear whether this sentence type is part of standard Spanish, as it was rejected by most of our Control group, as is shown in Section V. For these reasons, I consider this sentence type ungrammatical. 
Table 2 Test items on reflexive passives and reflexive impersonals

\begin{tabular}{|c|c|c|c|c|c|}
\hline \multirow{3}{*}{$\begin{array}{l}\text { Sentence type } \\
\text { a) Grammatical } \\
\text { reflexive passives } \\
\text { with pre-verbal } \\
\text { [-animate] } \\
\text { subject DP }\end{array}$} & \multicolumn{5}{|l|}{ Example } \\
\hline & $\begin{array}{l}\text { Unas casas } \\
\text { some houses }\end{array}$ & & $\begin{array}{l}\text { construyeron } \\
\text { built-PL }\end{array}$ & $\begin{array}{l}\text { para vender. } \\
\text { to sell }\end{array}$ & \\
\hline & \multicolumn{5}{|c|}{ 'Some houses were built to sell.' } \\
\hline $\begin{array}{l}\text { b) Ungrammatical } \\
\text { reflexive passives } \\
\text { with pre-verbal } \\
\text { [-animate] } \\
\text { subject DP }\end{array}$ & $\begin{array}{l}\text { *Unas casas } \\
\text { some houses }\end{array}$ & $\begin{array}{l}\text { se } \\
\text { SE }\end{array}$ & $\begin{array}{l}\text { construyó } \\
\text { built-sG }\end{array}$ & $\begin{array}{l}\text { para vender. } \\
\text { to sell }\end{array}$ & \\
\hline $\begin{array}{l}\text { c) Grammatical } \\
\text { reflexive }\end{array}$ & & & & para impedir & $\begin{array}{l}\text { nuevos } \\
\text { crímenes. }\end{array}$ \\
\hline impersonals with & \multirow{2}{*}{ 'The Garcías w } & A & the Garcías & to impede & new crimes \\
\hline $\begin{array}{l}\text { post-verbal } \\
\text { [+animate }] \\
\text { object DP }\end{array}$ & & ere a & rrested in order & r to impede new & crimes.' \\
\hline $\begin{array}{l}\text { d) Ungrammatical } \\
\text { reflexive passive }\end{array}$ & *Se arrestaron & $a$ & los García & para impedir & $\begin{array}{l}\text { nuevos } \\
\text { crímenes. }\end{array}$ \\
\hline $\begin{array}{l}\text { with impersonals } \\
\text { with [+animate] } \\
\text { subject DP }\end{array}$ & SE arrested-PL & A & the Garcías & to impede & new crimes \\
\hline
\end{tabular}

Source: Bruhn de Garavito 1999a: 269-72

Table 3 Number of subjects who accepted grammatical and ungrammatical items

\begin{tabular}{lcccc}
\hline Sentence type & Control & $\begin{array}{l}\text { Near-native } \\
\text { French }\end{array}$ & $\begin{array}{l}\text { Near-native } \\
\text { English }\end{array}$ & $\begin{array}{c}\text { Advanced } \\
\text { English }\end{array}$ \\
\hline $\begin{array}{l}\text { a) Grammatical reflexive } \\
\text { passives with pre-verbal } \\
\text { [-animate] subject DP }\end{array}$ & $6 / 6$ & $4 / 4$ & $2 / 2$ & $1 / 7$ \\
$\begin{array}{l}\text { b) Ungrammatical reflexive } \\
\text { passives with pre-verbal }\end{array}$ & $0 / 6$ & $0 / 4$ & $0 / 2$ & $0 / 7$ \\
$\begin{array}{l}\text { c) Grammate] subject DP } \\
\text { impersonals with post-verbal }\end{array}$ & $9 / 11$ & $10 / 11$ & $6 / 10$ & $2 / 10$ \\
$\begin{array}{l}\text { d+animate] object DP } \\
\text { d) Ungrammatical reflexive } \\
\text { passives with post-verbal }\end{array}$ & $5 / 11$ & $6 / 10$ & $2 / 10$ & $6 / 10$ \\
{$[+$ animate] subject DP } & & & & \\
\hline
\end{tabular}

Source: Bruhn de Garavito, 1999a; 1999b

Control group and in the experimental groups accepted grammatical reflexive passives with a pre-verbal [-animate] subject DP (a), with the exception of the Advanced English group. On the other hand, none of the groups accepted ungrammatical reflexive passives with a pre-verbal [-animate] subject DP (b). As for grammatical reflexive impersonals with a post-verbal [+animate] object DP (c), only the Control group 
and the French near-native group have a high acceptability rate; the Advanced English group performed the worst on this sentence type. Finally, several participants accepted (ungrammatical) reflexive passives with a post-verbal [+ animate] subject DP preceded by the objectmarking preposition $a(\mathrm{~d})$. The only group that seemed to behave a bit differently from all the others is the Advanced English group. This is likely to be the result of its lower proficiency level.

Bruhn de Garavito (1999a; 1999b) concludes that the near-native groups are indistinguishable from native speakers on most constructions and, thus, that L2 learners can acquire the structural properties involved in the use of reflexive passives and reflexive impersonals. Yet, on reflexive passives with a post-verbal [+animate] DP preceded by the object-marking preposition $a(\mathrm{~d})$, such a conclusion might not be warranted, since this sentence type is subject to dialectal variation. In view of the fact that Bruhn de Garavito's (1999a; 1999b) Control group is clearly not homogeneous - it includes participants from a variety of Spanish-speaking countries - it is possible that the participants' judgements in this group vary as a result of dialectal variation. On the other hand, Bruhn de Garavito (1999a) does not mention which variety of Spanish her L2 subjects had been exposed to when they learned Spanish. In particular, it is not clear whether they failed to reject ungrammatical reflexive passives with a post-verbal [ + animate] subject DP preceded by $a$ (d) as a result of dialectal variation or because they have not acquired the structural properties associated with this construction. For this reason, it is necessary to look at (a greater number of) L2 learners who were exposed only to standard Spanish in order to determine whether they can acquire the structural (and thematic) properties involved in reflexive passives and reflexive impersonals.

\section{The experiment}

\section{Research questions and predictions}

The general research questions addressed in this study are:

- Do advanced (L1 French and English) L2 learners of Spanish show grammatical knowledge of the different properties underlying 
reflexive passives and reflexive impersonals? If so, are they indistinguishable from native speakers?

- Does L1 (French or English) shape L2 learners' interlanguage grammar? If so, how?

If L2 learners have acquired the structural and thematic properties underlying se and the internal argument in Spanish reflexive passives, they will correctly assume that se checks accusative case and the internal argument checks nominative case. Likewise, if they have acquired the properties involved in the use of reflexive impersonals, they will know that se checks nominative case and the internal argument checks accusative case. They will also know that, because se is associated with the external $\theta$-role of the verb, neither reflexive passives nor reflexive impersonals can co-occur with an agentive PP. Finally, if the L1 shapes L2 learners' interlanguage grammar, it will be easier for French L2 learners of Spanish to acquire the properties of reflexive passives than for English learners, given the typological proximity of French and Spanish.

\section{Materials}

The participants of this study completed a grammaticality judgement task, whose format was based on Bruhn de Garavito's (1999a; 1999b) grammaticality judgement task. The test included 64 sentences: 20 grammatical items, 28 ungrammatical items and 16 distracters. The participants were asked to circle the number that best corresponded to their judgements with regard to specific sentences. The possible judgements included -2 ('sounds bad'), -1 (sounds bad, but not so much'), 0 ('you cannot decide: try to avoid this answer'), 1 ('sounds relatively good') and 2 ('sounds good'). The participants were specifically told not to pay attention to spelling, punctuation, style or elegance of the sentences. They were also asked to circle only one number and not change their answer after doing so. Table 4 summarizes the sentence types that were included in the task.

One set of grammatical and ungrammatical sentences tested whether L2 learners know that the internal argument of reflexive passives checks nominative case and triggers agreement on the verb (20a-b). Items included four grammatical (20a) and four ungrammatical sentences 


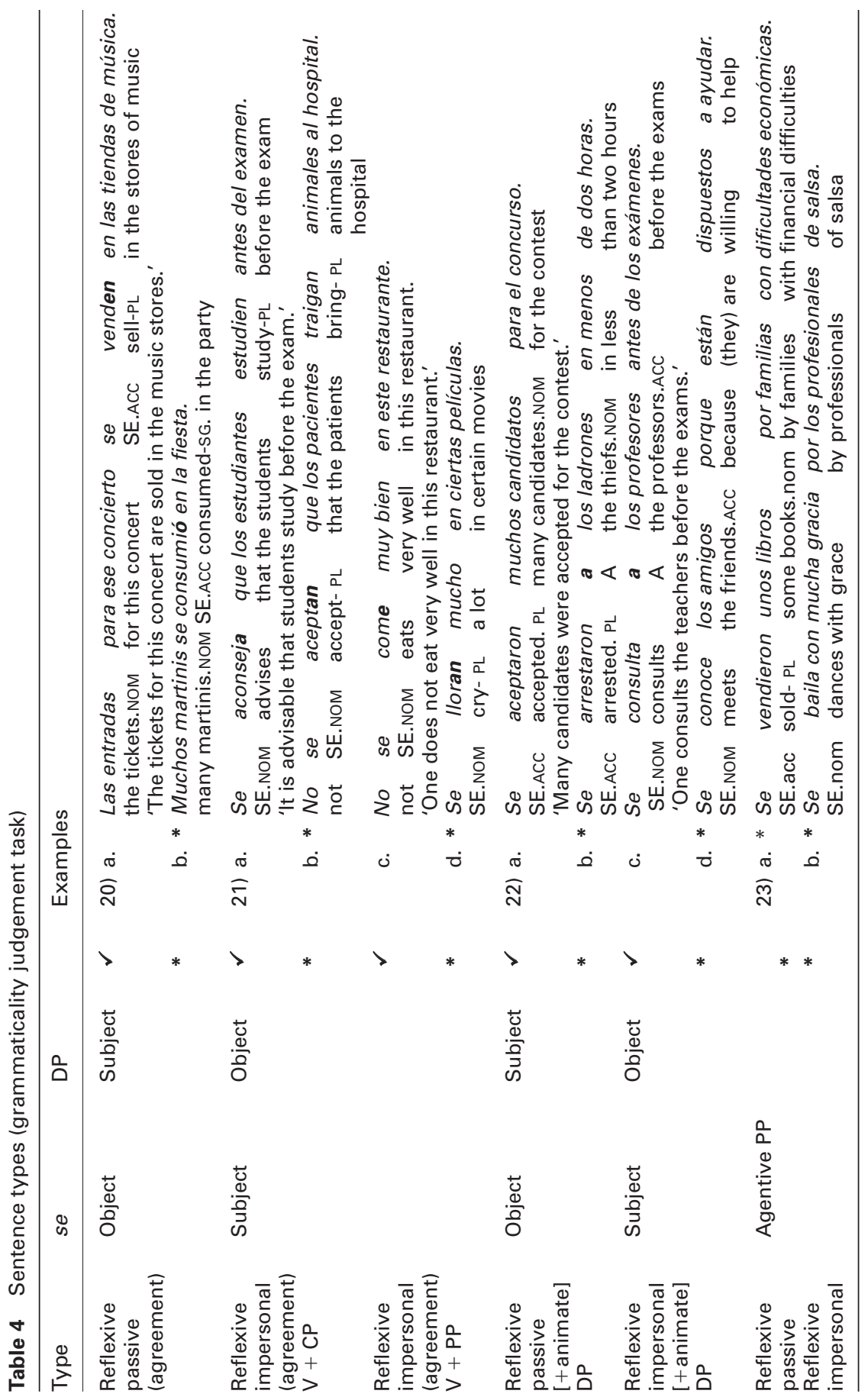


(20b), where the subject triggers agreement on the verb and where it does not, respectively. The DPs were singular in four sentences and plural in four others. This set of reflexive passives follows a canonical (DP-verb) word order and its DPs are all [-animate]..$^{10} \mathrm{~A}$ second set of grammatical and ungrammatical items tested the participants' knowledge of the structural properties of $s e$ in reflexive impersonals (21a-d), namely that it checks nominative case and triggers third person singular agreement on the verb. Items include 8 grammatical and 8 ungrammatical sentences, 8 with transitive verbs followed by a $\mathrm{CP}$ (henceforth, $\mathrm{V}+\mathrm{CP})(21 \mathrm{a}-\mathrm{b})$, and 8 with intransitive verbs followed by a PP (henceforth, V + PP) (21c-d). Grammatical items have the correct third person singular agreement, whereas ungrammatical items have third person plural agreement.

A third set of grammatical and ungrammatical sentences was used to determine whether participants were sensitive to the structural properties of a [+animate] DP in reflexive passives (i.e. that it checks nominative case) (22a-b) and in reflexive impersonals (i.e. that it checks accusative case) (22c-d). They included 8 reflexive passives and 8 reflexive impersonals with a plural [ + animate] DP appearing in postverbal position. In grammatical reflexive passives (22a), the DP was not preceded by the object marking preposition $a$, since it does not check accusative case; in ungrammatical reflexive passives (22b), the subject was preceded by $a$. As for reflexive impersonals, grammatical items (22c) were sentences where the object DP is preceded by the object marking preposition $a$, because it has the feature [ + animate] and checks accusative caseand ungrammatical items (22d) did not have such preposition. Reflexive passives also differ from reflexive impersonals in terms of subject-verb agreement, where the internal argument in the former triggers agreement on the verb, as opposed to in the latter. ${ }^{11}$ Finally, a fourth and last set of sentences tested whether the participants know that the external $\theta$-role (that of Agent) cannot be

\footnotetext{
${ }^{10}[+$ animate $]$ DPs were not included in these sentence types because the sentence would no longer receive a passive interpretation, but a reflexive/reciprocal one.

${ }^{11}$ Reflexive passives and reflexive impersonals with a [-animate] DP were not included in the present experiment. It was decided to limit the test items to obvious cases of grammaticality or ungrammaticality, based on standard Spanish and what subjects are instructed on in a classroom environment.
} 
overtly expressed in either reflexive passives or reflexive impersonal $(23 a-b)$. Sentences included four ungrammatical reflexive passives (23a) and four ungrammatical reflexive impersonals (23b) with an agentive PP introduced by por 'by'.

\section{Participants}

Two groups of third-year university-level Spanish students at the University of Ottawa were selected for this study. The final number of participants was 29: 13 native speakers of English and 16 native speakers of French, whose age ranged from 19 to 22 years, with the exception of one 26-year old and one 55-year-old participant $($ mean $=22 ; 3)$. Most participants had knowledge of either French or English as a second language. The level of proficiency of each experimental group in Spanish corresponded to the university level that the participants were in when the experiment was conducted: since they were taking the second course of the third-year Spanish level (sixth semester), they were classified at an advanced level of proficiency. ${ }^{12}$ The program in which the participants were enrolled included three hours of instruction weekly, which focused on grammar, written skills, comprehension and communicative interaction in the classroom. Grammar instruction was limited to textbook exercises. A review of the textbooks used within the Spanish program, as well as individual consultations with the Spanish teachers in the program, indicated that L2 learners had not received formal instruction on the differences between reflexive passives and reflexive impersonals. ${ }^{13}$

The results of the two experimental groups were compared to those of a Control group, made up of 27 native speakers of Spanish from Valladolid (Spain), ranging from 19 to 30 years of age (mean $=24 ; 9)$. Participants in the Control group were specialized in fields other than linguistics, started learning a second language only during high school and had very few contacts with other languages outside academic settings.

${ }^{12} \mathrm{I}$ am quite aware that as a result of this classification, the experimental groups might not be homogeneous.

${ }^{13}$ However, it is impossible to control for the kind of instruction that L2 learners might go and acquire outside the classroom. 


\section{Scoring procedures}

Mean scores were computed for each sentence type from the participants' grammaticality judgements (4 tokens per sentence type). In order to compute the mean scores, the participants' judgements (from -2 to +2 ) were simply averaged. The numbers of participants who provided accurate responses to grammatical and ungrammatical items are also provided. In order to compute the latter, grammatical judgements (1 'sounds relatively good' and 2 'sounds good') were collapsed, as were ungrammatical judgements ( -1 'sounds bad, but not so much' and -2 'sounds bad'). To be considered accurate, participants needed to provide three accurate judgements (i.e. grammatical or ungrammatical) out of four tokens. Statistical differences were established on the basis of the mean scores only.

\section{Results}

Figure 1 shows the total mean judgements of participants on grammatical and ungrammatical items for both reflexive passives and reflexive impersonals. A repeated-measures ANOVA performed on the mean grammaticality judgements, with grammaticality and sentence type as within-subject factors and language group as between-subject factor,

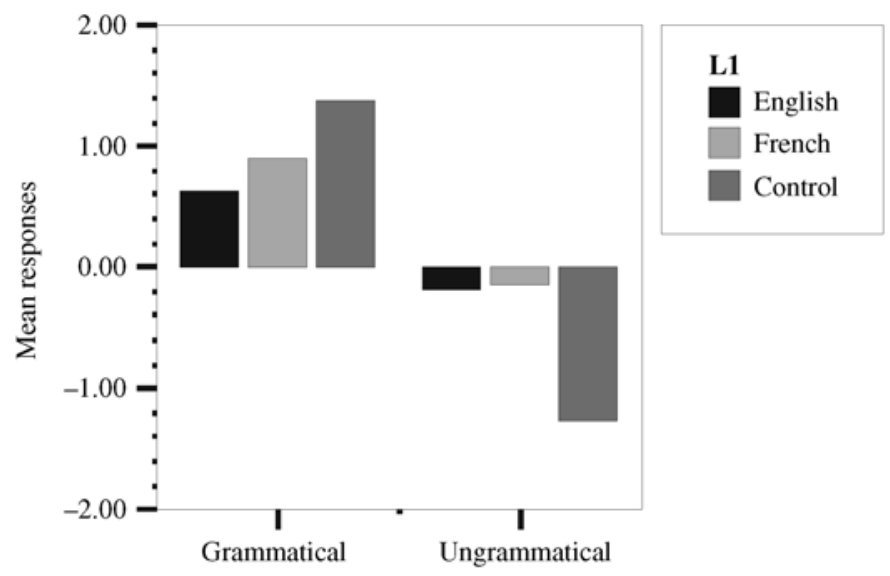

Sentences

Figure 1 Mean grammaticality judgements on reflexive passives and reflexive impersonals 
reveals a significant effect of grammaticality $(F(1,53)=255.356$, $p<.001)$ and of sentence type $(F(1,53)=6.835, p<.001)$, as well as a significant interaction between language group and both grammaticality $(F(2,53)=60.161, p<.001)$ and sentence type $(F(2,53)=5.978$, $p<.001) .{ }^{14}$ A post-hoc Tukey's HSD procedure the French and English groups performed significantly differently from the Control group on grammatical $(p(\mathrm{C} / \mathrm{E})=.002 ; p(\mathrm{C} / \mathrm{F})<.001)$ and ungrammatical items $(p<.001)$, but not from each other. Given the significant grammatically $\times$ language group interaction, repeated-measures ANOVAs were conducted separately for each experimental group to determine whether the grammaticality effect was significant. A significant grammaticality effect was found for both the English group $(F(1,12)=18.645, p<.001)$ and the French group $(F(1,15)=34.360$, $p<.001)$. Overall, the experimental groups were able to differentiate grammatical from ungrammatical items. Nevertheless, as the grammaticality $\times$ language group interaction suggests, the effect of grammaticality was different (i.e. here, weaker) for the experimental groups than for the control group.

The first set of sentences (20a-b) tested whether L2 learners would know that the internal argument in reflexive passives checks nominative case and triggers agreement on the verb. Figure 2 shows the participants'

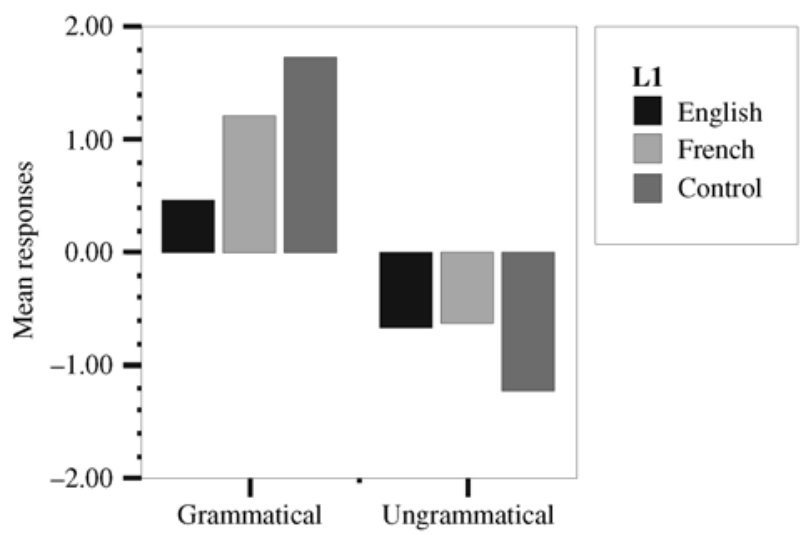

Sentences

Figure 2 Mean grammaticality judgements on reflexive passives testing agreement

\footnotetext{
${ }^{14}$ Since the sentences with an agentive pp (23 and 236) have no grammatical counter parts in the task, the mean judgements for these sentence types were not included in the repeated-measures ANOVA.
} 
mean scores on grammatical and ungrammatical items of this kind. A repeated-measures ANOVA performed on the mean grammaticality judjements reveals a main effect of grammaticality $F(1,53)=179.948$, $p<.001)$ and a significant interaction between grammaticality and language group $(F(2,53)=14.993, p<.001)$. The Tukey's HSD procedure reveals a significant difference between all the language groups on grammatical items $(p(\mathrm{C} / \mathrm{E})<.001 ; p(\mathrm{C} / \mathrm{F})=.033 ; p(\mathrm{E} / \mathrm{F})=.006)$, but no difference between the groups on ungrammatical items. Given the significant grammaticality $\times$ language group interaction, planned pairedsamples comparisons using the Bonferroni procedure were performed to ensure that the grammaticality effect was significant for the two experimental groups. The statistic shows that this was indeed the case $(p(\mathrm{E})=.004 ;(p(\mathrm{~F})<.001)$. These results indicate that L2 learners judged grammatical items statistically differently from ungrammatical items, despite the fact that the two experimental groups differ significantly from the Control group on grammatical items. The French group outperformed the English group on grammatical items, but the experimental groups do not differ from each other on ungrammatical items.

Table 5 reports the number of participants in each group who provided an accurate judgement on sentences (20a) and (20b). A look at the participants' accuracy rates shows that over half of the participants in the French group and in the Control group performed accurately on grammatical and ungrammatical items (separately), in contrast to the participants in the English group. Yet, few L2 learners provided the appropriate grammaticality contrasts between reflexive passives with agreement and reflexive passives without agreement. The French group outperformed the English group on these sentence types.

The second set of sentences (21a-d) was used to determine whether L2 learners would know that se in reflexive impersonals checks nominative case and triggers a third person singular agreement on the

Table 5 Number of participants who provided an accurate judgement on reflexive passives testing agreement

\begin{tabular}{lccr}
\hline & Grammatical & Ungrammatical & Both \\
\hline English & $6 / 13$ & $5 / 13$ & $2 / 13$ \\
French & $12 / 16$ & $9 / 16$ & $7 / 16$ \\
Control & $26 / 27$ & $23 / 27$ & $23 / 27$ \\
\hline
\end{tabular}




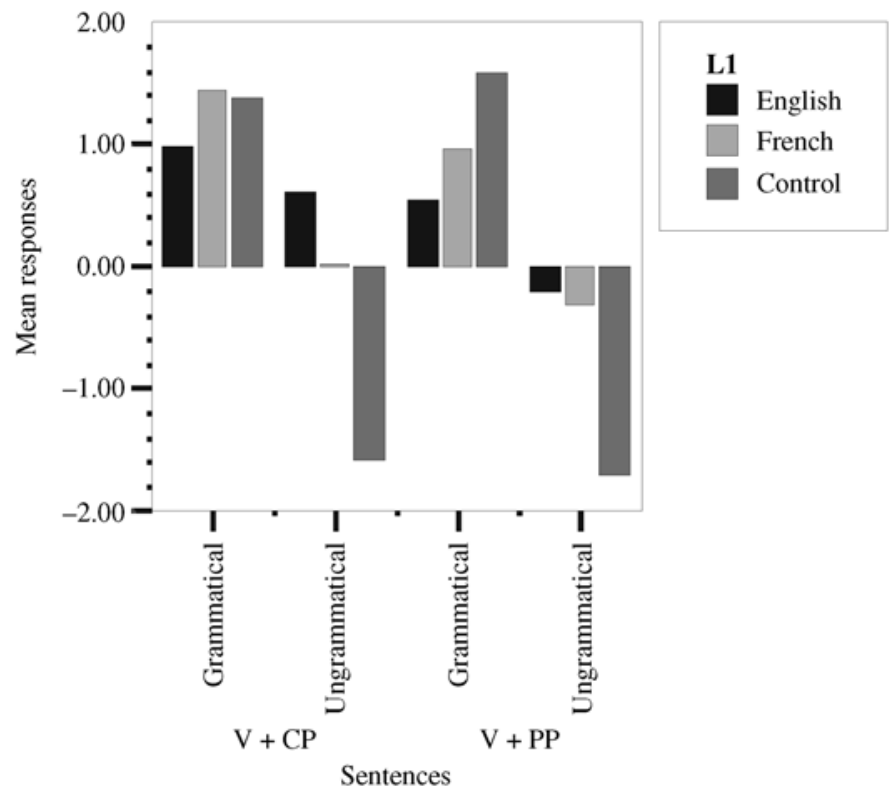

Figure 3 Mean grammaticality judgements on reflexive impersonals testing agreement

verb. Figure 3 shows the participants' mean scores on impersonals with transitive $(\mathrm{V}+\mathrm{CP})$ and intransitive $(\mathrm{V}+\mathrm{PP})$ verbs. A repeatedmeasures ANOVA conducted on the mean grammaticality judgements reveals a significant effect of grammaticality $(F(1,53)=237.660$, $p<.001)$ and a significant grammaticality $\times$ language group interaction $(F(2,53)=55.654, p<.001)$. The Tukey's HSD procedure indicates a significant difference between the English group and the control group on grammatical items $(p<.001)$, and between the experimental groups and the control group on ungrammatical items $(p<.001)$. Paired samples comparisons performed on the results of the experimental groups using the Bonferroni procedure reveal a significant effect of grammaticality only for the French group $(p<.001)$. These results show that only the French group was able to distinguish grammatical from ungrammatical reflexive impersonals with either a transitive or an intransitive verb. As shown in Figure 3, the English group could do so only on reflexive impersonals with a transitive verb.

Table 6 summarizes the number of participants in each group who provided an accurate judgement on grammatical and ungrammatical 
Table 6 Number of participants who provided an accurate judgement on reflexive impersonals testing agreement

\begin{tabular}{|c|c|c|c|c|c|c|}
\hline & \multicolumn{3}{|c|}{$V+C P$} & \multicolumn{3}{|c|}{$V+P P$} \\
\hline & Grammatical & Ungrammatical & Both & Grammatical & Ungrammatical & Both \\
\hline English & $10 / 13$ & $1 / 13$ & $1 / 13$ & $5 / 13$ & $7 / 13$ & $2 / 13$ \\
\hline French & $15 / 16$ & $6 / 16$ & $5 / 16$ & $11 / 16$ & $6 / 16$ & $4 / 16$ \\
\hline Control & $26 / 27$ & $23 / 27$ & $22 / 27$ & $26 / 27$ & $27 / 27$ & $26 / 27$ \\
\hline
\end{tabular}

reflexive impersonals testing agreement. The participants' accuracy rates show that over half of the participants in both experimental groups performed accurately on grammatical reflexive impersonals followed by a $\mathrm{CP}$, and over half of the participants in the French group and the Control group provided an accurate judgement on grammatical reflexive impersonals with intransitive verbs. In contrast, few L2 learners performed accurately on ungrammatical items, with the exception of the English group on ungrammatical reflexive impersonals with an intransitive verb followed by a PP. Crucially, very few L2 learners provided the appropriate contrasts between grammatical and ungrammatical items. These results show that ungrammatical items were more problematic for L2 learners than grammatical items, with most L2 learners failing to provide the correct grammaticality contrasts.

The third set of sentences $(22 \mathrm{a}-\mathrm{d})$ tested whether the participants would know that the [+animate] internal argument in reflexive passives must not be preceded by the object marking preposition $a$ as it checks nominative case, in contrast to reflexive impersonals, where it must be preceded by $a$ as it checks accusative case. Figures 4 and 5 show the mean scores of participants on reflexive passives and reflexive impersonals with a post-verbal [+animate] DP. A repeated-measures ANOVA conducted on the mean grammaticality judgments reveals a significant effect on grammaticality $(F(1,53)=63.430, p<.001)$ and a significant grammaticality $\times$ language group interaction $(F(2,53)=39.013, p<.001)$. This time, the Tukey's HSD procedure does not indicate a significant difference between any of the groups. Paired-samples comparisons on the results of the experimental groups using the Bonferroni procedure reveal a significant effect of grammaticality only for the English group's results on the reflexive passive 
54 Spanish reflexive passives and reflexive impersonals

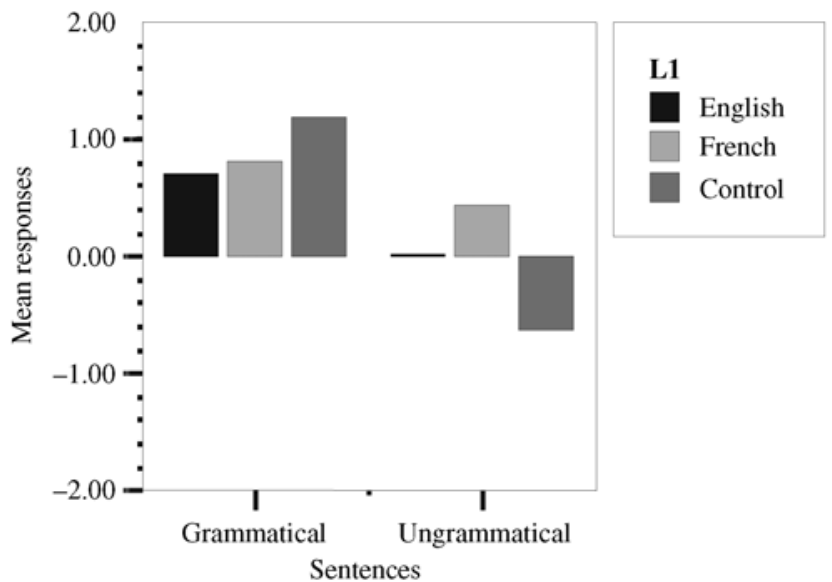

Figure 4 Mean grammaticality judgements on reflexive passives with a [+animate] DP
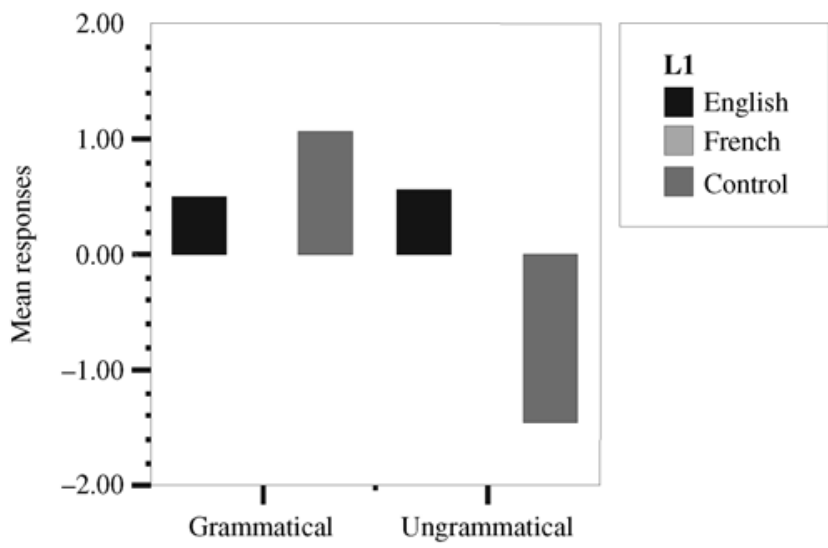

Sentences

Figure 5 Mean grammaticality judgements on reflexive impersonals with a [+animate] DP

$(p=.011)$. Hence, the L2 learners judged both grammatical and ungrammatical items more or less the same, either as grammatical or marginal.

Table 7 indicates the number of participants who provided an accurate judgement on reflexive passives and reflexive impersonals with a post-verbal [+animate] DP. The participants' accuracy rates show that other than on grammatical reflexive passives, very few L2 
Table 7 Number of participants who provided an accurate judgement on reflexive passives and reflexive impersonals with a post-verbal [+animate] DP

\begin{tabular}{lrrrrrrr}
\hline & \multicolumn{3}{c}{ Reflexive passive } & & \multicolumn{3}{c}{ Reflexive impersonal } \\
\cline { 2 - 3 } & Grammatical & Ungrammatical & Both & & Grammatical & Ungrammatical & Both \\
\hline English & $7 / 13$ & $3 / 13$ & $0 / 13$ & & $4 / 13$ & $2 / 13$ & $1 / 13$ \\
French & $9 / 16$ & $4 / 16$ & $0 / 16$ & & $4 / 16$ & $4 / 16$ & $0 / 16$ \\
Control & $23 / 27$ & $21 / 27$ & $15 / 27$ & $21 / 27$ & $24 / 27$ & $18 / 27$ \\
\hline
\end{tabular}

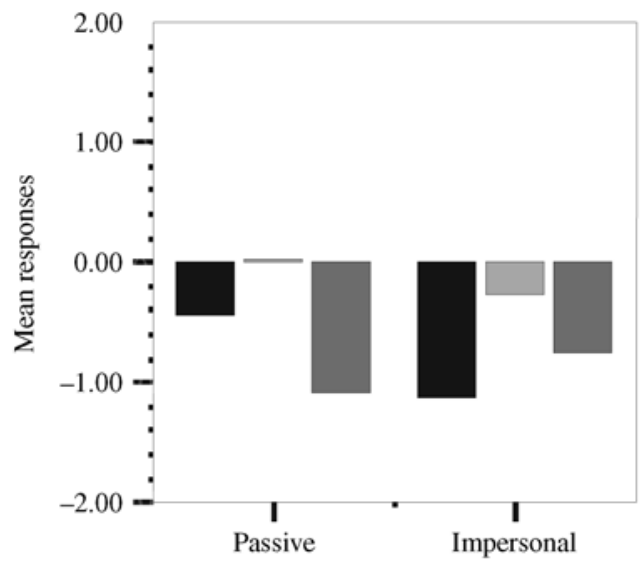

English

French

Control

Sentences

Figure 6 Mean grammaticality judgements on reflexive passives and reflexive impersonals with an agentive PP

learners in each experimental group performed accurately on grammatical and ungrammatical reflexive passives and reflexive impersonals with a post-verbal [+animate] DP preceded or not by the preposition $a$. In addition, virtually none of the participants provided the appropriate contrasts between grammatical and ungrammatical items. Even the Control group's responses are lower than one would expect, a point to which I return in the discussion section. Overall, neither of the experimental groups was able to distinguish grammatical from ungrammatical items.

The fourth set of sentences was used to determine whether L2 learners would know that the external $\theta$-role or Agent cannot be overtly expressed in either reflexive passives or reflexive impersonals, as it is already associated with se. Figure 6 shows the mean scores of participants on both ungrammatical reflexive passives and ungrammatical 
Table 8 Number of participants who provided an accurate judgement on reflexive passives and reflexive impersonals with an agentive PP

\begin{tabular}{lcc}
\hline & Reflexive passive & Reflexive impersonal \\
\hline English & $6 / 13$ & $9 / 13$ \\
French & $3 / 16$ & $6 / 16$ \\
Control & $23 / 27$ & $22 / 27$ \\
\hline
\end{tabular}

reflexive impersonals. Since the two sentence types are ungrammatical, no repeated-measures AVOVA was performed on the results. The Tukey's HSD procedure indicates a significant difference only between the French group and the control group $(p=.001)$. Hence, the English group was better at categorizing both reflexive passives and reflexive impersonals with an agentive PP as ungrammatical.

Table 8 gives the number of participants who provided an accurate judgement on these sentence types. A look at the participants' accuracy rates indicates that less than half of the participants in each experimental group performed accurately on reflexive passives and reflexive impersonals with an agentive $\mathrm{PP}$, with the exception of the participants in the English group on reflexive impersonals. On these sentence types, the French group seemed more willing than any other group to accept an agentive PP in both reflexive passives and reflexive impersonals.

Finally, and most importantly, a look at the participants' accuracy rate across sentence types indicates that none of the participants in either experimental group provided the appropriate grammaticality contrasts across sentence types.

\section{Discussion}

The present study aimed to address the question of whether advanced French and English L2 learners of Spanish show grammatical knowledge of the different properties underlying se and the internal argument in reflexive passives and reflexive impersonals and, if so, whether they are indistinguishable from native speakers. The results of this experiment can be discussed in terms of L2 learners' mean scores on the grammaticality judgement task and their accuracy rates on grammatical and ungrammatical items. 
On the one hand, the mean scores indicate that on reflexive passives and reflexive impersonals testing agreement, L2 learners were in general able to distinguish grammatical from ungrammatical items, although on most sentence types they performed significantly differently from the Control group. This, however, is not true of reflexive passives and reflexive impersonals with a post-verbal [+animate] DP preceded or not by the object-marking preposition $a$, where no significant difference was found between grammatical and ungrammatical items, with L2 learners failing to reject the latter. On reflexive passives and reflexive impersonals with an agentive PP, only the English group provided accurate (ungrammatical) judgements. In general, the experimental groups seem to have experienced greater difficulty in recognizing the ungrammatical items as ungrammatical.

On the other hand, a look at the participants' accuracy rates indicates that few L2 learners performed accurately on most sentence types, with the exception of:

- grammatical reflexive impersonals $(\mathrm{V}+\mathrm{CP})$ and grammatical reflexive passives with a post-verbal [+animate] DP, where over half of the participants in each experimental group provided accurate judgements;

- reflexive passives testing agreement and reflexive impersonals $(\mathrm{V}+\mathrm{PP})$, where over half of the participants in the French performed accurately; and

- (ungrammatical) reflexive impersonals with an agentive PP, where over half of the participants in the English group provided accurate judgements.

In addition, most L2 learners failed to provide the appropriate contrasts between grammatical and ungrammatical items, and those who did failed to do so consistently across sentence types.

With such results, it is clear that at this point in the L2 acquisition process, none of the participants in the French or English group has acquired the structural and thematic properties of se and the internal argument in either reflexive passives or reflexive impersonals. An obvious source of difficulty comes from reflexive passives and reflexive impersonals with a [+animate] DP and the presence or absence of the object-marking preposition $a$. Possibly, the fact that the sentence 
type *Se arrestaron $\underline{a}$ los ladrones en menos de dos horas 'The thieves were arrested in less than two hours' (22b) is accepted in some dialects of Spanish might have induced L2 learners to accept ungrammatical reflexive passives with a post-verbal [+animate] DP preceded by $a$. This may also be why the number of participants in the Control group who provided the expected judgements on this sentence type is lower than one would anticipate. On the other hand, grammatical or ungrammatical reflexive impersonals with a post-verbal [+animate] DP - e.g. Se consulta a los profesores antes de los exámenes 'One consults the teachers before the exams' (22c); *Se conoce los amigos, porque están dispuestos a ayudar 'One meets friends because they are willing to help' (22d)) - have not (to my knowledge) been reported to be subject to dialectal variation. It is thus not clear why the Control group's grammaticality judgements on these sentence types are not as high as one would anticipate. ${ }^{15}$ Given these results, it is probably not realistic to expect L2 learners to provide accurate judgements on these sentence types. Nevertheless, in order to conclude that they have acquired the properties of se and the internal argument in reflexivepassive and reflexive impersonals, L2 learners should at least be indistinguishable from native speakers, which was not the case. The fact that these sentences vary from one dialect to another has perhaps contributed to their general difficulty with both constructions.

Alternatively, it is possible that L2 learners have not yet mastered the use of the object-marking preposition $a$. As neither French nor English marks accusative [+animate] DPs with a preposition, the presence or absence of such preposition might be completely irrelevant in the L2 learners' interlanguage grammar. That the L2 acquisition of this preposition is problematic has indeed been acknowledged in other studies (e.g. Liceras, 1994). Yet, if this were the sole cause of L2 learners' poor performance on the task, better results would have been found in reflexive passives and reflexive impersonals without a [+animate] internal argument. I have shown that very few L2 learners provided the appropriate grammaticality contrasts on several other sentence types. Hence, it seems that L2 learners do not (yet) show knowledge of the structural and thematic properties of se and the internal argument in either reflexive 
passives or reflexive impersonals. Their proficiency level might not have been advanced enough at the time of testing.

This study also attempted to address the question of whether L1 (here, French and English) shapes L2 learners' interlanguage grammar. The mean scores indicate few instances of significant differences between the French and the English groups. The French group significantly outperformed the English group only on grammatical reflexive passives with a pre-verbal [-animate] DP testing agreement $(p=.005)$. More differences were found in L2 learners' accuracy rates, with the French group outperforming the English group also on ungrammatical reflexive passives testing agreement. These sentences have one element in common: they tested L2 learners' knowledge of the nominative-case checking of the internal argument and the agreement it triggers on the verb. The fact that French has richer agreement than English seems to have helped the French group on these test items. A greater effect of L1 was not observed, perhaps because most L2 learners had some knowledge of either French or English as a second language. Another possibility is that L2 learners at an advanced level of proficiency might not rely so much on their L1 when operating in the target language.

It is difficult to make a direct comparison between the results of this experiment and those of Bruhn de Garavito (1999a; 1999b), since they differ in terms of participants (namely their level of proficiency), test items, and experimental design. One comparison that can be established is between her advanced group (L1 English) and our English group. ${ }^{16}$ The participants in Bruhn de Garavito's study responded to her grammaticality judgement task more or less like the English group in this experiment: in both experiments, L2 learners performed better on grammatical items than on ungrammatical ones. This discrepancy is more salient for grammatical and ungrammatical reflexive passives involving agreement in Bruhn de Garavito's experiment than in ours. Ungrammatical reflexive passives with a post-verbal [+animate] DP preceded by the object-marking preposition $a$ were also problematic for her experimental groups as well as her Control group. Grammatical

\footnotetext{
${ }^{16}$ Naturally, there is a possibility that the level of proficiency of the advanced group in Bruhn de Garavito (1999a; 1999b) is not equivalent to that of our English group.
} 
reflexive impersonals with a post-verbal [+animate] DP preceded by $a$, on the other hand, were problematic only for her advanced and near-native English groups. In this case, dialectal variation alone cannot explain the difficulty that her two English groups encountered with reflexive passives and reflexive impersonals involving a post-verbal [+animate] DP, as the great majority of the participants in her Control group accepted this sentence type (see Table 3). This suggests that the L2 acquisition of the object-marking preposition $a$, as well as of the constructions at issue, is subject to difficulties even at near-native levels of proficiency.

Of course, the present study is not without limitations. First, the two experimental groups of this study might not be homogeneous, since their level of proficiency in Spanish was not assessed independently. Second, although the textbooks that the L2 learners used within the Spanish program (i.e. over three years) did not include grammar lessons on what differentiates reflexive passives from reflexive impersonals, one cannot control for the instruction that the participants might have received outside the classroom. Finally, firmer conclusions could have been drawn had the L2 learners' knowledge of agreement and of the use of the object-marking preposition $a$ been assessed independently.

\section{Conclusions}

The present study investigated the L2 acquisition of Spanish reflexive passives and reflexive impersonals by French- and English-speaking adults at an advanced level of proficiency. I have shown that Spanish reflexive passives and reflexive impersonals instantiate a potential learnability problem, because:

- the constructions are superficially very similar (se V DP) but display distinct idiosyncratic morphological and syntactic behaviour;

- neither exists in English, and the reflexive impersonal does not exist in French; and

- differences between the two are typically not subject to explicit instruction.

The results of the grammaticality judgement task indicated that L2 learners have not (yet) acquired the structural and thematic properties 
underlying se and the internal argument in either construction. These results contrast with the findings of studies showing that adult L2 learners come to know subtle grammatical properties of the target language that are not present in the L1 nor salient in the input (e.g. Schreiber and Sprouse, 1998; Kanno, 1999; Dekydtspotter and Sprouse, 2001). The proficiency level of L2 learners in this study is perhaps not advanced enough for them to have acquired the structural and thematic properties involved in the use of reflexive passives and reflexive impersonals, since the input to which they are exposed is limited to classroom time. The results of this study confirm that the L2 acquisition of Spanish reflexive passives and reflexive impersonals by native French and English speakers is difficult, even at an advanced level of proficiency.

\section{Acknowledgements}

Previous versions of this article were presented at the Linguistic Symposium on Romance Languages (LSRL-34, University of Utah, March 2004) and at the 7th conference on Generative Approaches to Second Language Acquisition (GASLA-7, Indiana University, April 2004). I would like to thank the audiences of LSRL-34 and GASLA-7 for their valuable comments on this research. I would also like to thank Juana M. Liceras for her assistance with the experiment and Bonnie D. Schwartz for her useful comments in the writing of this article. I would like to express my gratitude to Robert Bley-Vroman, Craig Chaudron and Kamil Ud Deen for their valuable comments on how to improve the content of this article. Special thanks must also go to Cristina Senn and Alberto Villamandos, who collected the data for the two experimental groups, and to Raquel Fernandez Fuertes, who collected the data for the Control group in Spain. Thanks must go to Christian Abello Contesse and Mercedes Torres Cansino for their comments on the varieties of Spanish in Spain. Finally, I would like to thank the anonymous Second Language Research reviewers for their valuable comments on the first version of this article.

\section{References}

Belletti, A. 1982: Morphological passive and pro-drop: the impersonal construction in Italian. Journal of Linguistic Research 2, 1-34. 
Bosque, I. and Demonte, V. 1999: Gramática descriptiva del español [Descriptive grammar of Spanish]. Tome 2. Espasa.

Bruhn de Garavito, J.L.S. 1999a: The se construction in Spanish and nearnative competence. Spanish Applied Linguistics 3, 247-95.

1999b: The syntax of Spanish multifunctional clitics and near-native competence. Unpublished $\mathrm{PhD}$ dissertation, McGill University, Montreal.

Burzio, L. 1986: Italian syntax. Reidel.

Chomsky, N. 1995: The minimalist program. MIT Press.

Dekydtspotter, L. and Sprouse, R.A. 2001: Mental design and (second) language epistemology: Adjectival restrictions of wh-quantifiers and tense in English-French interlanguage. Second Language Research 17, $1-35$.

Dobrovie-Sorin, C. 1998: Impersonal se constructions in Romance and the passivization of unergatives. Linguistic Inquiry 29, 399-437.

Hernanz, M.L. and Brucart, J.M. 1987: La sintaxis [Syntax]. Editorial critica.

Kanno, K. 1999: Acquisition of verb gapping in Japanese by Mandarin and English speakers. In Kanno, K., editor, The acquisition of Japanese as a second language. John Benjamins, 159-73.

Liceras, J.M. 1994: La teoría sintáctica y los juicios de gramaticalidad: la positión del sujeto en español [Syntactic theory and grammaticality judgements: the subject position in Spanish]. Revista Canadiense de Estudios Hispánicos 18, 219-55.

Montrul, S. 1997: Transitivity alternations in second language acquisition: across linguistic study of English, Spanish and Turkish. Unpublished $\mathrm{PhD}$ dissertation, McGill University, Montreal.

1999: 'Se' o no 'se': a look at transitive and intransitive verbs in Spanish interlanguage. Spanish Applied Linguistics 3, 145-94.

Olarrea, A. 1996: Pre and postverbal subjects positions in Spanish: a minimalist account. Unpublished $\mathrm{PhD}$ dissertation, University of Washington.

Ordóñez, F. 1997: Word order and clause structure in Spanish and other Romance languages. Unpublished PhD dissertation, CUNY.

Perlmutter, D.M. and Postal, P.M. 1984: Impersonal passives and some personal laws. In Perlmutter, D.M. and Rosen, C.G., editors, Studies in relational grammar. University of Chicago Press, 171-216.

Raposo, E. and Uriagereka, J. 1996: Indefinite SE. Natural Language and Linguistic Theory 14, 749-810.

Reinhart, T. and Reuland, E. 1993: Reflexivity. Linguistic Inquiry 24, $657-720$.

Rivero, M.L. 2001: On impersonal reflexives in Romance and Slavic and semantic variation. In Camps, J. and Wiltshire, C.R., editors, Romance syntax, semantics and L2 acquisition. Selected papers from the 30th Linguistic Symposium on Romance Languages, Gainesville, Florida, February 2000. John Benjamins, 169-95. 
Schreiber, T. and Sprouse, R.A. 1998: Knowledge of topicalization and scrambling in English-German interlanguage. McGill Working Papers in Linguistics 13, 162-71.

Schwartz, B.D. and Sprouse, R.A. 1994: Word order and nominative case in nonnative language acquisition: a longitudinal study of the L1 Turkish German interlanguage. In Hoekstra, T. and Schwartz, B., editors, Language acquisition studies in generative grammar. John Benjamins, 317-68.

1996: L2 cognitive states and the full transfer/full access model. Second Language Research 12, 40-72.

Toth, P.O. 1998: Linguistic and pedagogical perspectives on acquiring second-language morpho-syntax: a look of Spanish se. Unpublished $\mathrm{PhD}$ dissertation, University of Pittsburgh.

1999: Preemption in instructed learners of Spanish as a foreign language: acquiring a rule for se. Spanish Applied Linguistics 3, 195-245.

Tremblay, A. 2002: The L2 acquisition of Spanish reflexive passives and reflexive impersonals by French- and English-speaking adults: does explicit grammatical instruction make a difference? Unpublished MA dissertation, University of Ottawa. 